\title{
SERIAL ELECTROCARDIOGRAMS IN RHEUMATIC FEVER
}

\author{
BY \\ B. GANS \\ From the Miller General Hospital, London.
}

(Received for Publication September 9, 1950)

The management of a patient with acute rheumatic fever depends mainly on the presence or absence of carditis. Numerous tests are available to determine whether or not the heart is affected but none is entirely satisfactory. Taran (1946) found that in $25 \%$ of children with active carditis the commonly used tests gave negative results.

As the rheumatic process results in irritation or depression of the myocardium (Pardee, 1947), electrocardiographic abnormalities would be expected to occur often. Since Parkinson, Gosse, and Gunson (1920) described electrocardiographic and polygraphic abnormalities in patients with acute rheumatic fever, almost every part of the electrocardiographic curve has been found to be affected during some phase of the disease. Orgain, Martin, and Anderson (1941) reviewed the abnormalities described, and found their reported incidence to vary from $22 \%$ to $100 \%$, depending on the number of records taken in each case. Cohn and Swift (1924) noted frequent prolongation of the A-V conduction time, Blackman and Hamilton (1948) placed most reliance on changes in the ST segment, and Master (1931) commented on the importance of $\mathrm{T}$ wave changes. Taran and Szilagyi (1947) and Abrahams (1949) found prolongation of QTc* in $100 \%$ and $90 \%$ respectively of their cases. Pokress and Goldberger (1949), however, found QTc increased in only $28 \%$ of their cases of acute rheumatic fever, and $30 \%$ ' never showed $\mathrm{K}$ that even reached normal values.' Finally, changes similar to those found in acute rheumatic carditis occur in the electrocardiograms of patients suffering from non-rheumatic infections (Joos and Yu, 1950). It is clear from these investigations that the electrocardiogram in acute rheumatic fever is not diagnostic, and that the changes observed are transient.

If, however, during the course of rheumatic fever a large number of electrocardiograms are obtained, the opportunities for observing these fleeting

* $\mathrm{QTc}=$ Bazett's (1920) constant $\mathrm{K}=\frac{\mathrm{Q}-\mathrm{T}}{\sqrt{\overline{\text { cycle }}}}$ abnormalities are greatly increased. Serial electrocardiograms help in assessing progress. Minor changes in records taken at frequent intervals become obvious. The changes may only be suggestive of cardiac damage in any one record, but their evolution and regression prove that the rheumatic process is active. The most commoniy observed alterations are in the ST segments and the $T$ waves. They can be seen at a glance, and no lengthy calculations are necessary, as for the determination of QTc. Once the disease process has become quiescent, serial tracings will show no further change, as the electrocardiogram in normal persons is strikingly constant over long periods of time (Rothschild, Sacks, and Libman, 1927; Cohn, and Swift, 1924; and others). By means of serial electrocardiograms it is also possible to determine whether a patient who has had a streptococcal infection is likely to develop rheumatic fever, as electrocardiographic evidence often precedes by days or weeks the development of clinical rheumatic fever (Rantz, Boisvert, and Spink, 1945). Finally, it may be worth while pointing out that children much prefer electrocardiographic examinations to the unavoidable needle pricks when estimating the sedimentation rate.

The following seven cases have been selected to show the type of electrocardiographic change that is commonly found. From each patient daily records were obtained for the first week after admission, and thrice weekly thereafter until the patient was either discharged or transferred to a long-stay hospital. All records were taken on a standard string galvanometer with the patient recumbent, and the string tension was standardized to give $10 \mathrm{~mm}$. deflection on $1 \mathrm{~m} . \mathrm{V}$. For the determination of $K$ the average length of $C$ and QT was calculated by measuring all complexes in leads I and II. As changes in the precordial leads are also transient and non-specific (Levy and Bruenn, 1934; Ash, 1945), only one example of alterations in a chest lead (CR4) is reproduced. It is recommended that prints be obtained from the films as this simplifies comparison. 
12-1-49

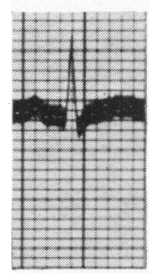

14-2-49

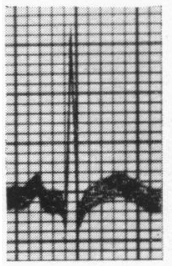

29-3-50

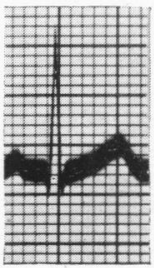

14-1-49

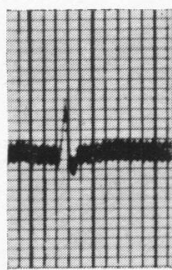

$16-2-49$

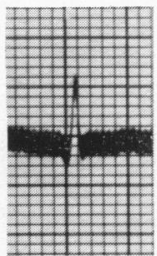

$31-3-50$

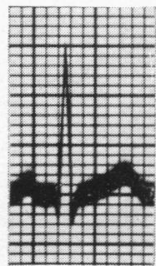

19-1-49

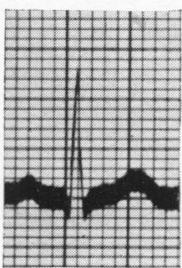

$10-3-49$

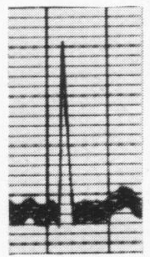

$3-5-50$

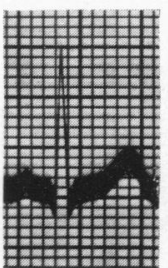

21-1-49

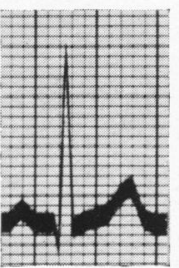

5-4-49

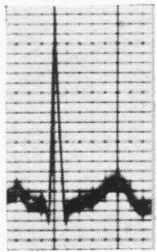

$30-5-50$

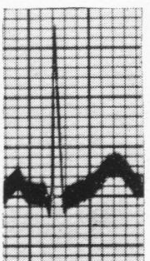

FIG. 1.-All complexes lead II.
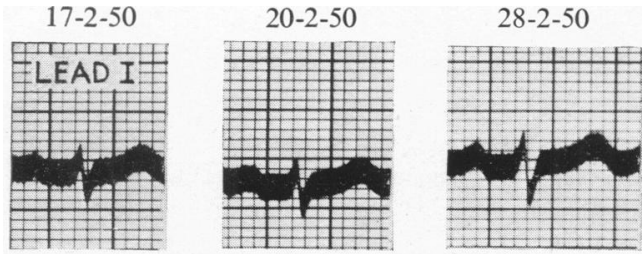

21-3-50
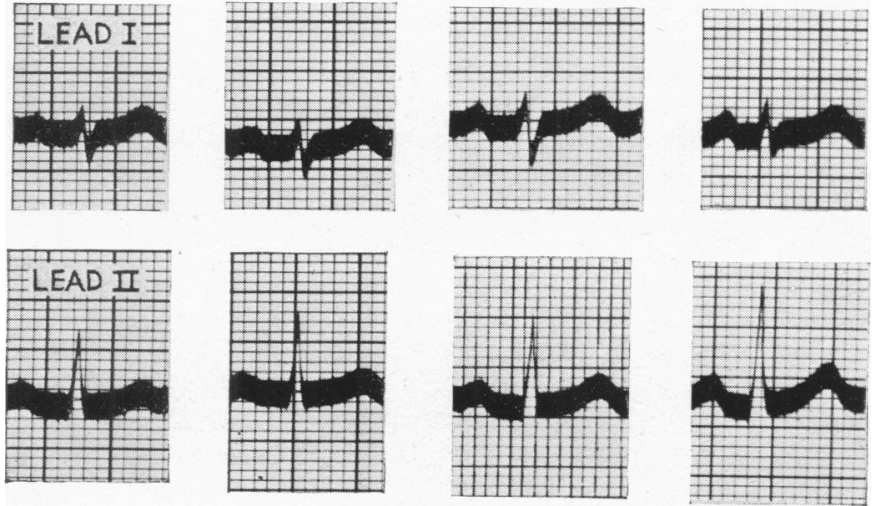

FIG. 2.

$13-5-49$

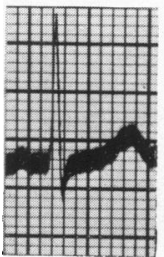

$15-5-49$

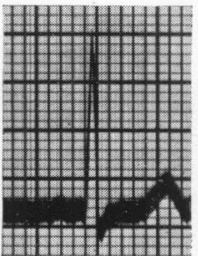

$16-5-49$

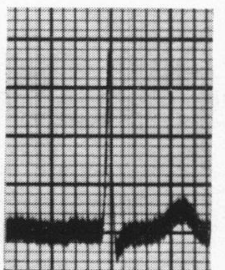

2-2-49

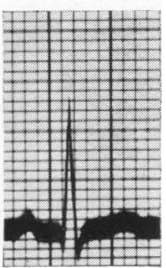

$17-6-49$

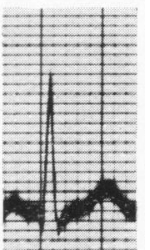

$25-8-50$

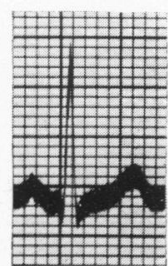

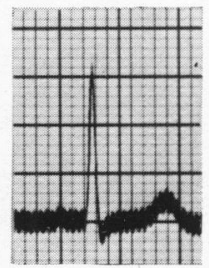

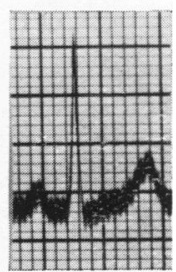


$19-5-50$
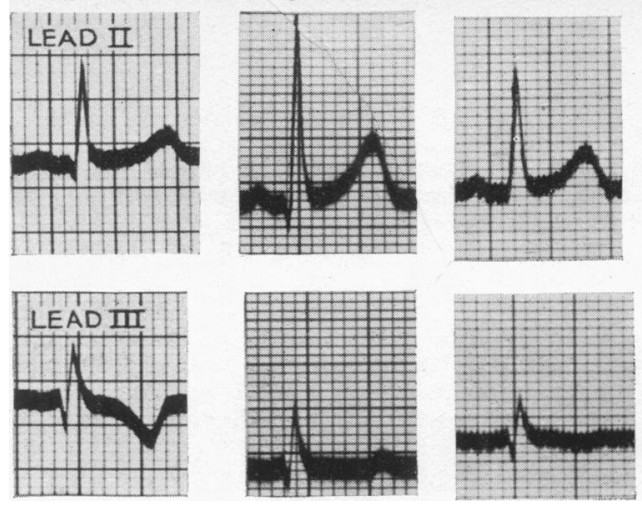

FIG. 4.

30-4-49
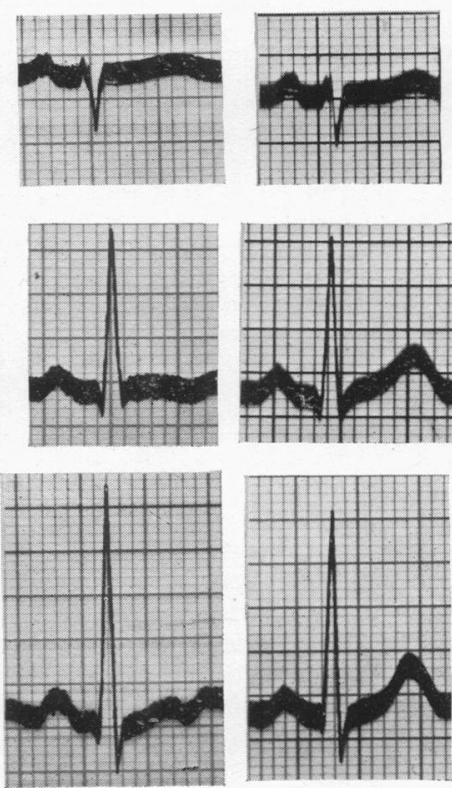

30-9-49

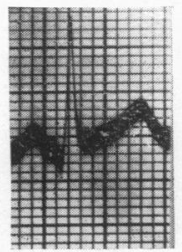

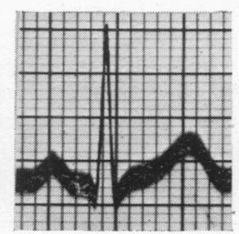

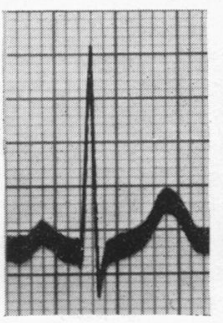

7-10-49

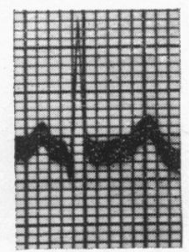

$14-7-50$
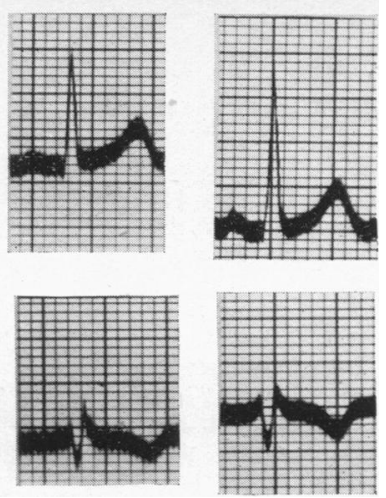
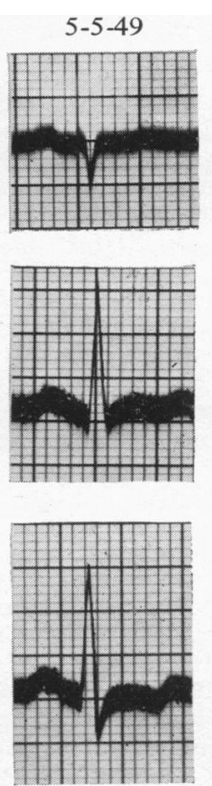
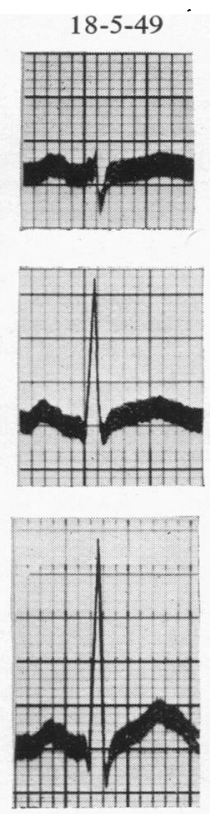

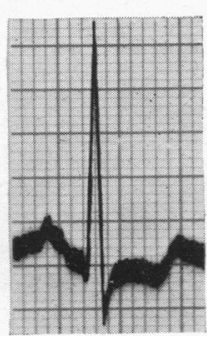

FIG. 5.

$$
\text { 12-10-49 }
$$

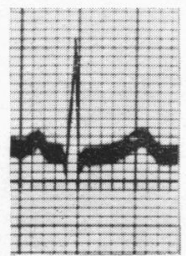

14-10-49

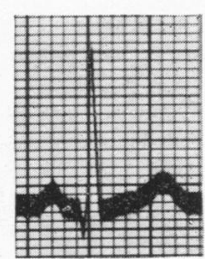

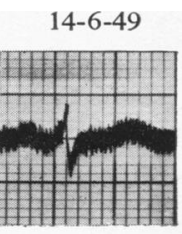
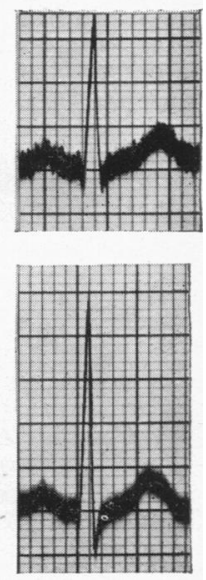

Fig. 6.

12-6-49

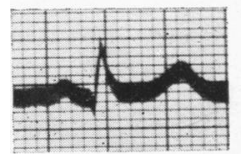

13-6-49

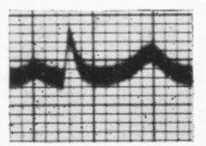

21-6-49

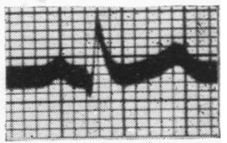

Fig. 7.-All complexes lead I. 


\section{Illustrative Case Summaries}

Case 1. A boy, aged 10, was admitted on January 11, 1949 , with swollen and painful joints, rheumatic carditis, and rheumatic nodules. The temperature was $100^{\circ} \mathrm{F}$., sleeping pulse 130, Hb. $60 \%$, W.B.C. 20,000, E.S.R. $30 \mathrm{~mm}$. $/ \mathrm{hr}$. A throat swab showed a growth of haemolytic streptococci.

Serial records show waxing and waning of changes in the ST segment and the T wave (Fig. 1).

On June 17 all signs of activity had disappeared, the electrocardiogram was normal, and the child was discharged.

The value for $K$ during the active carditis ranged from $3 \cdot 19$ to $3 \cdot 92$.

The child was readmitted on March 29, 1950, with an attack of anaphylactoid purpura and joint pains. There were no clinical or electrocardiographic signs of carditis, and though the symptoms lasted for two months, the ECG remained unchanged, and has done so since.

Case 2. A girl, aged 10, was admitted on February 17, 1950, with joint pains, rheumatic carditis, rheumatic nodules, and erythema marginatum. The ECG showed changes in the amplitude of $S$ in lead $I$, and of $R$ in lead II (Fig. 2). There were alterations in the contour of ST and in the height of T in lead II. The P-R interval decreased from $0 \cdot 20$ to $0 \cdot 16$. The values for $K$ were $3 \cdot 82,4 \cdot 33,4 \cdot 11,4 \cdot 45$. The carditis was still active at the time of transfer.

Case 3. A girl, aged 7, was admitted on May 12, 1950, with flitting joint pains, no abnormal signs in the heart, and slight splenomegaly.

The sedimentation rate was $17 \mathrm{~mm}$. $/ \mathrm{hr}$, the temperature $98 \cdot 8^{\circ} \mathrm{F}$., and sleeping pulse 90 . Symptoms and signs disappeared after ten days, and she has remained well.

The ECG showed disappearance and reappearance of $P$, and a steady decrease of $S$ (Fig. 3). The record has remained unchanged since June 22,1950 . The values for $\mathrm{K}$ were $4 \cdot 08,3 \cdot 54,3 \cdot 84,3 \cdot 68,3 \cdot 80$.

Case 4. A girl, aged 13, had had scarlet fever for four weeks, and pain in one hip for a week before admission. On admission there were no abnormal signs in joints or heart. The temperature was normal, the sleeping pulse 70, and E.S.R. $6 \mathrm{~mm}$./hr. She was discharged, but readmitted 11 days later with classical rheumatic fever; a systolic murmur at the apex; temperature $99 \cdot 2^{\circ}$ F.; the sleeping pulse 110 ; E.S.R. $30 \mathrm{~mm} . / \mathrm{hr}$. The ECG at the time of first admission (May 19) was considered normal, but compared with later tracings showed flat $\mathbf{P}$ and raised ST in lead II, and a high $\mathbf{R}$ in lead III (Fig. 4). On readmission $T_{3}$ had become positive and slowly reverted to negative as the disease progressed. The gradual disappearance of $\mathrm{Q}_{2}$, the return of $\mathrm{ST}_{2}$ to isoelectric level, and a decrease in $\mathbf{R}_{3}$ were noted. The values for $K$ were $3 \cdot 66,3 \cdot 82,3 \cdot 83,3 \cdot 97,3 \cdot 80$.

Case 5. A boy, aged 10, was admitted with rheumatic fever, enlarged heart, systolic and soft diastolic apical murmurs. The temperature was $100 \cdot 2^{\circ} \mathrm{F}$., the sleeping pulse 125, and E.S.R. $53 \mathrm{~mm} . / \mathrm{hr}$. The child had improved by April 30, 1949, but relapsed on May 4, and then made a steady recovery. There were marked changes in ST and T in all leads (Fig. 5) (There was no clinical evidence of pericarditis.) P-R was prolonged only once (April 25), when it was $0.18 \mathrm{sec}$. at a rate of 112. At the time of discharge the child was symptomfree and apyrexial (sleeping pulse 70, E.S.R. $10 \mathrm{~mm} . / \mathrm{hr}$.). The values for $\mathrm{K}$ were $4 \cdot 20,4 \cdot 13,4 \cdot 28,4 \cdot 06,4 \cdot 12,4 \cdot 08$.

Case 6. A girl, aged 6, was admitted with pains in the ankles, and systolic and soft diastolic apical murmurs. The temperature was $99^{\circ} \mathrm{F}$., the sleeping pulse 90-100, and E.S.R. $15 \mathrm{~mm}$./hr. A throat swab gave a culture of haemolytic streptococci.

She settled down rapidly and was discharged after one month.

The ECG showed progressive raising and lowering of the ST segment, and changes in its contour (Fig. 6). Records taken after October 14, 1949, showed no further change. The values for $K$ were $3 \cdot 63,4 \cdot 10,4 \cdot 03,3 \cdot 96$.

Case 7. A boy, aged 7, was admitted with a history of recurrent chorea and a systolic murmur at the apex. The temperature was normal, the sleeping pulse 80 , and E.S.R. $4 \mathrm{~mm}$. $/ \mathrm{hr}$. There were moderate choreic movements.

There was a family history of rheumatic fever. The cardiac signs remained unchanged during his hospital stay, and the chorea had ceased at the time of discharge. The very slight changes in the contour and slope of ST justified the conclusion that the heart had been involved by the rheumatic process (Fig. 7). The values for $\mathbf{K}$ were $4 \cdot 02,3 \cdot 86,3 \cdot 80$, and the curve remained unchanged during the follow-up period.

\section{Summary}

It is the purpose of this paper to emphasize the importance and simplicity of taking serial electrocardiograms for the evaluation of the progress of carditis in acute rheumatic fever. Whilst no individual change in the electrocardiographic curve is necessarily diagnostic, the occurrence of changes from record to record during the course of the disease is of value in deciding how the patient should be managed. Once no further change can be seen in successive tracings, the carditis has ceased. It is suggested that standard limb lead electrocardiograms be obtained daily during the early course of the carditis, and three times a week thereafter.

I wish to express my thanks to Miss Ellis of the Lewisham Hospital for her help in printing the electrocardiograms.

\section{REFERENCES}

Abrahams, D. G. (1949). Brit. Heart J., 11, 342. Ash, R. (1945). Amer. J. Dis. Child., 70, 277. Bazett, H. C. (1920). Heart, 7, 353.

Blackman, N. S., and Hamilton, C. I. (1948). Ann. intern. Med., 29, 416.

Cohn, A. E., and Swift, H. F. (1924). J. exp. Med., 39, 1.

Joos, H. A., and Yu, P. N. G. (1950). Amer. J. Dis. Child., 80, 22. 
Levy, R. L., and Bruenn, H. G. (1934). Proc. Soc. Exp. Biol., N. Y., 32, 559.

Master, A. M. (1931). Amer. J. med. Sci., 181, 211.

Orgain, E. S., Martin, J. M., and Anderson, H. I. G. (1941). Amer. J. Dis. Child., 62, 26.

Pardee, H. E. B. (1947). Amer. J. Med., 2, 528.

Parkinson, J., Gosse, A. H., and Gunson, E. B. (1920). Quart.J. Med., 13, 363.
Pokress, J. M., and Goldberger, E. (1949). Amer. Heart J., 38, 423.

Rantz, L. A., Boisvert, P. J., and Spink, W. W. (1945). Arch. intern. Med., 76, 131.

Rothschild, M. A., Sacks, B., and Libman, E. (1927). Amer. Heart J., 2, 356.

Taran, L. M. (1946). J. Pediat., 29, 77.

, and Szilagyi, N. (1947). Amer. Heart J., 33, 14. 